\title{
POIKILODERMA OF CIVATTE
}

\author{
by Uladzimir P. Adaskevich, Maryia A. Katina, Valeryia A. Miadzelets
}

comment:

Anca Chiriac MD, PhD

Nicolina Medical Center, Department of Dermatology Iasi-Romania

E-mail: ancachiriac@yahoo.com

Prof. Caius Solovan

University of Medicine, V Babes Timisoara, Romania

Source of Support:

Nil

Competing Interests:

None

Our Dermatol Online. 2013; 4(2): 188

Date of submission: 22.03.2013 / acceptance: 28.03.2013

\section{Cite this article:}

Anca Chiriac, Caius Solovan: comment: Poikiloderma of Civatte. Our Dermatol Online. 2013; 4(2): XX

This clinical entity is not uncommon in Romania, especially in spring and summer,(but also during winter, for whose who are very fond of sky), most frequently diagnosed in fair-skin women over 40 years old, on a genetic background, after sun exposure (varying from minutes to hours), with a great cosmetic and physiological impact on social life. It is still a problem for dermatologists, not mainly for diagnosis but for therapy.

It is an easy clinical diagnosis, although many other dyspigmentations must be ruled out (see classification).

\section{Classification of facial and neck melanosis [1]:}

* Melasma (chloasma)

* Erythema dyschromicum perstans (Ashy dermatosis of Ramirez, erythema chronicum figuratum melanodermicum)

* Lichen planus pigmentosus

* Riehl's melanosis (Pigmented cosmetic/ contact dermatitis)

* Erythromelanosis peribuccale pigmentaire of Brocq

* Poikilodermia Civatte

* Erythromelanosis follicularis of face and neck

* Nevus of Ota

* Miscellaneous causes: Periorbital Melanosis

Addison's disease

Exogenous ochronosis

Post chikungunya pigmentation (reported in India, induced by alpha virus transmitted by Aedes aegypti and Aedes albopictus)

Acanthosis nigricans
In daily practice a skin biopsy is vary rare necessary for diagnosis, a through endocrinological examination is mandatory, sometimes an allergology test or a very attentive anamnesis are helpful (cosmetics involved).

The mainstay of the treatment is photoprotection, which must be very clearly explained to the patients, the rules regarding the use of sunscreens have to be followed carefully and even so the avoidance of pick hours on sunlight (10 am-4pm) must be strictly accepted.

There are no guidelines for the management of Poikilodermia Civatte so, different, and sometimes combined therapies, have been applied with success in treating this condition, aspect very well presented in the article.

We prefer Hydroquinone and chemical peels (Azelaic acid and Kojic acid) along with laser therapy.

We congratulate the authors for presenting the case, which turned to be an open door to an up-to date overview on Poikilodermia Civatte.

\section{REFERENCES}

1. Khanna N, Rasool S: Facial melanoses: Indian perspective. Indian J Dermatol Venereol Leprol. 2011;77:552-64. 